\title{
2012 Canadian Guidelines for the diagnosis and management of fibromyalgia syndrome: Executive summary
}

\author{
Mary-Ann Fitzcharles $M B C h B^{1,2}$, Peter A Ste-Marie BA ${ }^{2,3}$, Don L Goldenberg $\mathrm{MD}^{4}$, John X Pereira $\mathrm{MD}^{5}$, \\ Susan Abbey $\mathrm{MD}^{6}$, Manon Choinière $\mathrm{PhD}^{7}$, Gordon $\mathrm{Ko} \mathrm{MD}^{8}$, Dwight E Moulin $\mathrm{MD}^{9}$, Pantelis Panopalis $\mathrm{MD}^{1}$, \\ Johanne Proulx ${ }^{10}$, Yoram Shir MD²; the National Fibromyalgia Guideline Advisory Panel
}

M-A Fitzcharles, PA Ste-Marie, DL Goldenberg, et al; the National Fibromyalgia Guideline Advisory Panel. 2012 Canadian guidelines for the diagnosis and management of fibromyalgia syndrome: Executive summary. Pain Res Manag 2013;18(3):119-126.

BACKGROUND: Recent neurophysiological evidence attests to the validity of fibromyalgia (FM), a chronic pain condition that affects $>2 \%$ of the population.

OBJECTIVES: To present the evidence-based guidelines for the diagnosis, management and patient trajectory of individuals with FM.

METHODS: A needs assessment following consultation with diverse health care professionals identified questions pertinent to various aspects of FM. A literature search identified the evidence available to address these questions; evidence was graded according to the standards of the Oxford Centre for Evidence-Based Medicine. Drafted recommendations were appraised by an advisory panel to reflect meaningful clinical practice.

RESULTS: The present recommendations incorporate the new clinical concepts of FM as a clinical construct without any defining physical abnormality or biological marker, characterized by fluctuating, diffuse body pain and the frequent symptoms of sleep disturbance, fatigue, mood and cognitive changes. In the absence of a defining cause or cure, treatment objectives should be patient-tailored and symptom-based, aimed at reducing global complaints and enhancing function. Healthy lifestyle practices with active patient participation in health care forms the cornerstone of care. Multimodal management may include nonpharmacological and pharmacological strategies, although it must be acknowledged that pharmacological treatments provide only modest benefit. Maintenance of function and retention in the workforce is encouraged.

CONCLUSIONS: The new Canadian guidelines for the treatment of FM should provide health professionals with confidence in the complete care of these patients and improve clinical outcomes.

Key Words: Clinical care; Fibromyalgia; Pain; Practice guidelines

\section{Lignes directrices canadiennes 2012 pour le diagnostic et le traitement du syndrome de fibromyalgie : Résumé}

HISTORIQUE : Les récentes données probantes neurophysiologiques attestent de la validité de la fibromyalgie (FM), un trouble chronique qui touche plus de $2 \%$ de la population.

OBJECTIFS : Présenter les lignes directrices fondées sur des données probantes pour diagnostiquer, prendre en charge et suivre la trajectoire individuelle des patients ayant une FM.

MÉTHODOLOGIE : Une évaluation des besoins après une consultation auprès de divers professionnels de la santé a permis de soulever des questions pertinentesrelativement à divers aspects de la FM. Une analyse bibliographique a ensuite permis de répertorier les données probantes sur le sujet. Les chercheurs les ont classées selon les normes du Oxford Centre for Evidence-Based Medicine. Un groupe consultatif a examiné les recommandations rédigées pour refléter les pratiques cliniques éloquentes.

RÉSULTATS : Les présentes recommandations incluent les nouveaux concepts cliniques de la FM sans anomalie physique ou marqueur biologique défini, caractérisés par des douleurs corporelles diffuses et fluctuantes et des symptômes fréquents de perturbations du sommeil, de fatigue, de fluctuations d'humeur et de changements cognitifs. En l'absence de cause définie ou de traitement curatif, les objectifs thérapeutiques devraient être adaptés aux patients et fondés sur les symptômes, en vue de réduire les problèmes globaux et d'améliorer la fonction. Un mode de vie sain, ainsi que la participation active des patients aux soins, forme la pierre angulaire des soins. La prise en charge multimodale peut inclure des stratégies non pharmacologiques et pharmacologiques, mais il faut admettre que les bienfaits des traitements pharmacologiques sont modestes. On préconise le maintien de la fonction et la rétention en milieu de travail. CONCLUSIONS : Les nouvelles lignes directrices canadiennes pour le traitement de la FM devraient donner confiance aux professionnels de la santé quant aux soins complets de ces patients, tout en améliorant les issues cliniques.

with the best available evidence (3). The clinical challenge remains because the cause of, the ideal treatment and any potential cures for FM are unknown. In addition, diagnosis is entirely dependent on patient report of symptoms and functional impairment, without any defining physical or laboratory abnormality.

In addition to the pivotal symptom of chronic widespread pain, FM syndrome often includes fatigue, nonrestorative sleep, cognitive dysfunction and mood disorder, as well as variable somatic symptoms (4). Canadian prevalence rates are in the order of $2 \%$ to $3 \%$, with females

A though fibromyalgia (FM) has been recognized as a clinical synfor the past two decades, recent neurophysiological evicontroversy surounding FM stems from the subjective nature of plaints and lack of any defining abnormal biological findings $(1,2)$ This newer understanding has prompted clinical study and exploration of newer treatment options. In this spirit, the 2012 Canadian Guidelines for the diagnosis and management of FM syndrome were developed to provide directions for optimal patient care that align

\footnotetext{
${ }^{1}$ Division of Rheumatology, McGill University; ${ }^{2}$ Alan Edwards Pain Management Unit, McGill University Health Centre; ${ }^{3}$ Faculty of Law, Université de Montréal, Montreal, Quebec; ${ }^{4}$ Division of Rheumatology, Tufts University School of Medicine, Boston, Massachusetts, USA; ${ }^{5}$ Department of Family Medicine, Faculty of Medicine, University of Calgary, Calgary, Alberta; ${ }^{6}$ Department of Psychiatry, Faculty of Medicine, University of Toronto, Toronto, Ontario; ${ }^{7}$ Centre de la recherche du Centre hospitalier de l'Université de Montréal, Department of Anesthesiology, Faculty of Medicine, Université de Montréal, Montreal, Quebec; ${ }^{8}$ Division of Physiatry, University of Toronto, Toronto; ${ }^{9}$ Departments of Clinical Neurological Sciences and Oncology, University of Western Ontario, London, Ontario; ${ }^{10}$ Patient representative Correspondence: Dr Mary-Ann Fitzcharles, Montreal General Hospital, McGill University Health Centre, 1650 Cedar Avenue, Montreal, Quebec H3G 1A4. Telephone 514-934-1934 ext 44176, fax 514-934-8239, e-mail mary-ann.fitzcharles@muhc.mcgill.ca
} 
TABLE 1

Level of evidence grading table

\begin{tabular}{|c|c|c|c|c|c|}
\hline & Level 1 & Level 2 & Level 3 & Level 4 & Level 5 \\
\hline Diagnosis & $\begin{array}{l}\text { Systematic review of } \\
\text { cross-sectional studies }\end{array}$ & $\begin{array}{l}\text { Systematic review of cross- } \\
\text { sectional studies with } \\
\text { consistently applied } \\
\text { reference standard and } \\
\text { blinding }\end{array}$ & $\begin{array}{l}\text { Systematic review of } \\
\text { nonconsecutive studies or } \\
\text { studies without consistently } \\
\text { applied reference } \\
\text { standards }\end{array}$ & $\begin{array}{l}\text { Systematic review of } \\
\text { case-control studies or } \\
\text { cross-sectional studies } \\
\text { with nonindependent } \\
\text { reference standard }\end{array}$ & Opinion \\
\hline Treatments & $\begin{array}{l}\text { Systematic review of } \\
\text { randomized trials or n-of-1 } \\
\text { trials }\end{array}$ & $\begin{array}{l}\text { Randomized trial or } \\
\text { (exceptionally) } \\
\text { observational study with } \\
\text { dramatic effect }\end{array}$ & $\begin{array}{l}\text { Nonrandomized controlled } \\
\text { cohort/follow-up study }\end{array}$ & $\begin{array}{l}\text { Systematic review of case- } \\
\text { control studies or } \\
\text { historically controlled } \\
\text { studies }\end{array}$ & Opinion \\
\hline Outcome & $\begin{array}{l}\text { Systematic review of } \\
\text { inception cohort studies }\end{array}$ & Inception cohort studies & $\begin{array}{l}\text { Cohort or control arm of } \\
\text { randomized trial }\end{array}$ & $\begin{array}{l}\text { Systematic review of case } \\
\text { series }\end{array}$ & Opinion \\
\hline \multicolumn{6}{|c|}{ Grades of recommendation } \\
\hline A & \multicolumn{5}{|l|}{ Consistent level 1 studies } \\
\hline B & \multicolumn{5}{|c|}{ Consistent level 2 or 3 studies, or extrapolations from level 1 studies } \\
\hline
\end{tabular}

Level may be graded down on the basis of study quality, imprecision, indirectness, inconsistency between studies, or because the absolute effect size is very small; level may be graded up if there is a large or very large effect size. Adapted from reference 10

reportedly affected more commonly than males, but with likely underdiagnosis in males (5). Although it occurs most frequently in middle-age women, FM can also affect children, teenagers and elderly patients.

Diagnosis may be delayed for years, with increased health care costs related to excessive investigation, frequent health care visits and referral to multiple specialists. With direct health care costs for Quebec patients with FM estimated to be more than CAD $\$ 4,000$ per patient per year, an amount $30 \%$ higher than non-FM patients, an improved understanding of FM by the health care community may reduce patient suffering as well as the economic burden of this condition (6).

While there is currently no cure for FM, ideal management will address the combination of symptoms that may be present. Treatments must focus on active patient participation toward achieving healthrelated goals and incorporate nonpharmacological strategies as a foundation. Pharmacological treatment may also be required in a patient-tailored approach, with attention devoted to the risk-benefit ratio of any medication.

The Guidelines comprise 46 recommendations developed and arranged according to the subsections of diagnosis, management and follow-up (Appendix 1). Although there is copious literature available addressing various aspects of FM, the level of evidence available, other than for more recent drug studies, is mostly poor or lacking completely, with more than two-thirds of the recommendations graded as either level D or consensus. These guidelines are presented as recommendations pertinent to patient care in Canada, graded according to the level of supporting evidence, with the objective to facilitate clinical care. They should be viewed as an aid in the care of patients with FM, taking into consideration the unique needs of the individual, and should not be interpreted as the rules by which each patient should be managed.

\section{Process of guideline development}

The Guidelines were developed at the request of the Canadian Pain Society (CPS) to provide guidance for the diagnosis, management and patient trajectory of adults with FM in Canada, and the full document is available online through the CPS website (3). Because previous guidelines from the international community were based on available literature up to December 2006, updated guidance was needed in the light of recent progress in the understanding of FM (7-9).

Following a needs assessment with input from 139 Canadian health care professionals representing various disciplines, the Canadian Fibromyalgia Guideline Committee was assembled to oversee the guideline process. A literature search, directed by each question, was conducted at the McGill University Health Sciences library (Montreal Quebec). Databases searched were Embase, MEDLINE, PsycINFO,
PubMed and the Cochrane Library, for results published during a 20-year period between 1990 and July 2010. A manual search of the references cited by original studies, reviews and evidence-based guidelines was also performed. Evidence was assigned according to the strength of the literature, and recommendations were drafted and graded according to the classification system of the Oxford Centre for Evidence-Based Medicine (Table 1) (10). Drafted recommendations were submitted via the Internet to 35 of the original 139 individuals who agreed to participate and constituted the National Fibromyalgia Guidelines Advisory Panel. Recommendations receiving 80\% approval were accepted, while those not receiving approval were modified according to suggestions and resubmitted for voting. The document was reviewed by an external expert, as well as by the executive committees of the CPS and the Canadian Rheumatology Association, with resulting endorsement by both bodies. These guidelines will be in the governance of both endorsing bodies, who will oversee the updating process in 2015. All members of the Canadian Fibromyalgia Guideline Committee will participate in the dissemination process to enable maximum visibility across all relevant disciplines.

The needs assessment was supported by an unrestricted educational grant from Valeant (Montreal). The process of guideline development was facilitated by funding from the Louise and Alan Edwards Foundation. None of the funding sources had a role in the collection, analysis or interpretation of the data, or in the decision to publish the present report. Conflicts of interest for all members of the CFCG have been declared and are listed in the Guidelines document available online (3).

\section{The diagnosis of FM reflects a paradigm shift}

FM should now be positively diagnosed in the primary care setting following a comprehensive clinical evaluation and without need for unnecessary investigation. FM is recognized as a condition that fluctuates over time, and should no longer be viewed as an 'all or none' phenomenon, although factors influencing this variability in symptoms may not be easily identified. Chronic widespread pain, the pivotal and most important symptom, may have a burning quality suggestive of neuropathic pain, is not localized to any specific body tissue and tends to move from site to site. Symptoms of fatigue, sleep disturbance, cognitive changes, mood disturbance and various somatic symptoms may occur to a greater or lesser extent (4). Although many patients achieve some stability of this condition, symptoms seldom disappear completely (11).

A concept emphasized by these guidelines is that the diagnosis of FM should be made in the primary care setting and, in particular, does not require specialist confirmation. A second aspect that is highlighted 
is the fallacy associated with the tender point examination, a mainly subjective technique that is not supported by sound scientific basis and has been fraught with controversy. Therefore, contrary to previous beliefs, examination of tender points should not be used to either confirm or validate a diagnosis of FM (2). There is a strong call for the reduction of both excessive investigation and referrals to multiple specialists. Only simple laboratory tests should be performed, consistent with routine good health care, to ensure that some other, easily identifiable condition is not overlooked. The guidelines also acknowledge that criteria for the diagnosis of FM, developed by the American College of Rheumatology in 1990 and revised in 2010, were primarily intended for research purposes and should not be used to confirm a clinical diagnosis in an individual patient.

The clinical evaluation combined with simple blood tests will rule out most conditions that can present with body pain such as endocrine disease (hypothyroidism), rheumatic conditions (early inflammatory arthritis or polymyalgia rheumatica), neurological disease (myopathy or multiple sclerosis) or drug-induced conditions (lipid-lowering agents, aromatase inhibitors). Any additional testing should be specifically driven by the clinical findings, but with prudence.

Therefore, these guidelines recommend a paradigm shift whereby the responsibility for the diagnosis and management of FM is moved away from the specialist, with care concentrated in the primary care setting (12). Early diagnosis will avoid unnecessary investigations, a cause for patient uncertainty that prolongs health care behaviours and fosters medicalization (13-15). Attention can then be focused toward symptom management, attainment of optimal health, and maintenance or improvement of function. New symptoms in a patient with a previous diagnosis of FM should be evaluated according to good clinical standards, with the understanding that FM patients may eventually develop other illnesses unrelated to FM.

An elementary understanding of the neurophysiological concepts present in FM will reassure health care professionals of the validity of this condition and will also help guide rational treatment choices. Abnormalities in pain processing have been identified at various levels in the peripheral, central and sympathetic nervous systems, as well as the hypothalamo-pituitary-adrenal axis stress-response system, but these findings remain in the research domain and are not available for routine patient care (16-18).

The cause of FM is unknown. Familial studies have identified the possibility of genetic predisposition, with up to one-quarter of relatives of FM patients reporting chronic widespread pain $(19,20)$. While no individual gene has been associated with FM, there is increasing evidence of a polygenic effect, with genes affecting serotoninergic, catecholaminergic and dopaminergic systems likely playing a role $(21,22)$. Genetic factors may, therefore, predispose some individuals to a dysfunctional stress response via the hypothalamo-pituitary axis, and may be the setting whereby a triggering event may initiate clinical symptoms (23). Psychosocial distress, as well as early life adversity including abuse, have been shown to predict the onset of chronic, widespread pain $(24,25)$. Primed by genetic factors, a physical or psychological trigger, as reported for nearly one-quarter to one-third of individuals, may lead to clinical expression of FM (26). Therefore, the expression of FM may be explained by a biopsychosocial model in which predisposition, triggering and other factors, such as depression, maladaptive coping or fearavoidance behaviour, contribute to chronicity.

\section{The management of patients with FM}

In the absence of a cure for FM, treatment recommendations should be directed at reduction of symptoms and fostering optimal function, with patient outcome goals clearly defined. Symptom-based management, taking into consideration the heterogeneous nature of this condition, can help to direct a patient-tailored, multimodal approach (27). Ideal management requires active patient participation in healthrelated practices and will centre on nonpharmacological strategies. Pharmacological treatments may be helpful for some patients, but with a need to evaluate efficacy and side effect profile (28). With average responses to therapy mainly modest at best, the essence of current evidence is that there is no 'gold standard' of treatment. Self-efficacy, attention to psychological distress and adherence to global treatment recommendations, strategies that may be augmented by cognitive behavioural therapy, will favourably influence outcome (29). Patients should be encouraged to be self-sufficient, develop good coping skills and pursue as normal a life pattern as possible.

Regular physical activity should form the cornerstone of treatment and received the highest grade of recommendation. To facilitate adherence, exercise of the patient's choice is encouraged and should be adjusted according to the individual patient's ability. This may take the form of an aerobic, strengthening, water, home-based or group program, depending on availability for an individual patient. Although many patients with FM are using various complementary and alternative medicines, in the absence of evidence, none can be recommended, but disclosure by the patient should be encouraged.

Symptom-based treatment represents a rational approach to pharmacological choices, with drugs impacting more than one symptom adding an advantage $(16,27)$. There is a notion that the ideal treatment for FM is likely a combination of treatments, often in lower doses than reported in the study setting, with potential benefits of adherence. Although the traditional pharmacological treatment paradigm begins with the use of simple analgesics and tricyclic antidepressants, other agents that may be used include other antidepressants, gabapentinoids, dopaminergic agents and sleep modifiers. Once a drug treatment has been initiated, attention should be devoted to efficacy as well as the development of side effects, many of which can mimic symptoms of FM. Fatigue may be aggravated by gabapentinoids, antidepressants or analgesics; depression may be exacerbated by opioids and cannabinoids; gastrointestinal symptoms may be affected by nonsteroidal anti-inflammatory agents, opioids and antidepressants; and sleep disturbance may be aggravated by opioids and antidepressants.

Although care in a multidisciplinary setting may be desirable, this is not realistic, nor is it necessary for most patients (30). Access to a health care team member who is knowledgeable about FM can provide support, and may help the patient to develop coping strategies. Nursing support has been shown to reduce waiting time to consultation and increase patient satisfaction, but is still underused (31). Finally, public education and social marketing will help demystify FM and promote health.

\section{Patient trajectory and outcome in FM}

Ideal care of individuals with FM will be in the primary care setting; there is no clear advantage of care by a specialist (32-35). Because the primary care physician has the best knowledge of the patient from the biopsychosocial perspective and is likely to have been managing the patient over time, the primary care setting must be the focal point of management. The need for education in this regard is imperative to provide confidence in management.

The health care community should discourage passive health-related practices and excessive dependence on health care professionals. Although clinic visits may be more frequent at treatment initiation, reduction of unnecessary health care contact when the patient is on a stable trajectory is mandatory. Clinical response may be reliably measured by a simple assessment of patient global status, rather than recourse to cumbersome questionnaires $(36,37)$. Documenting patient goals and their levels of achievement is a strategy that has concrete meaning for a patient (38). Measurement of tender points is not a clinically relevant or reliable outcome measurement and should not be used to monitor patients (39).

Every effort should be made to maintain individuals with FM in the workforce. Their work ability is often contentious, with up to $35 \%$ receiving work disability benefits $(40)$. Work modification that may include pacing may be an avenue to help retain individuals in the workforce. Although the physical and psychological demands of a job influence employment, the life situation, attitude and motivation, and ability to influence work parameters are additional contributing factors (41). Although return to work is perceived as an ideal health 
economic outcome, this may not be applicable for many women with FM who may be homemakers (42).

FM is a condition associated with considerable direct and indirect health care costs. A positive diagnosis may reduce costs by reducing tests, imaging, medication use, specialist referrals and primary care visits (14). In the United States, the cost for service utilization in an individual FM patient was more than US $\$ 2,000$ in 1997, with reports in the order of CAD $\$ 4,000$ per year per patient for Canada and Europe (6,43-45). While nonpharmacological therapies have been demonstrated to be an effective and necessary component of treatment, they do, however, incur costs that are threefold greater than for pharmacological therapies. Comorbidities, such as depression, have also been shown to increase costs, warranting attention (44). Education and improved knowledge translation will enable health care professionals to diagnose and manage individuals with FM more effectively with associated cost containment.

\section{Limitations}

These recommendations should serve as a template for the care of adult FM patients, with the understanding that each patient is unique and treatments should be individualized. Evidence to support many aspects of these guidelines was either scanty or lacking, with reliance often placed on clinical experience and consensus of the participating health care professionals. Because access to care is not equal across all geographical regions of Canada, differences in care will be evident, with a need to harmonize treatments to the clinical setting. Although no cost analysis for the implementation of these guidelines has been performed, development of simple, clinically useful tools is in process. The full guideline document available on both the CPS and Canadian Rheumatology Association websites is extensive and should, therefore, serve as a reference, rather than a tool for day-to-day clinical practice.

We acknowledge that these guidelines propose fairly considerable changes in the way FM patients will be managed in the future. These suggestions may, at first, appear discomforting, but we believe that the medical community should be proactive in orchestrating the care of these patients. With a strong medical statement, policy makers and other stakeholders will be obliged to recognize this paradigm change.

\section{CONCLUSION}

FM is a valid syndrome affecting approximately one million Canadians. These guidelines address the complete spectrum of FM, are evidencebased, and were formulated by a large group of health care professionals representing various disciplines. They should provide direction for the rational treatment of FM, taking into consideration patient, provider and societal perspectives. It is hoped that the present report will help the health care community to confidently care for these patients with a positive approach that restores quality of life.

\section{SUMMARY}

The 2012 Canadian Guidelines for the diagnosis and management of fibromyalgia were developed by a multidisciplinary team and are based on the available published evidence. Recommendations reflect this evidence combined with rational clinical judgment to facilitate the clinical care of patients. Fibromyalgia is a valid diagnosis that is a clinical construct without any defining physical abnormality or biological marker. Ideal treatment encompasses both nonpharmacological and pharmacological strategies, with emphasis on maintaining function. Several areas of paradigm change are addressed including a shift of diagnosis and treatment from the specialist setting to primary care.

FINANCIAL SUPPORT: Louise and Alan Edwards Foundation (salary support for PSM) and Quebec Pain Society (French translation of guidelines).

CONFLICTS OF INTEREST: Conflicts of interest are documented in the 2012 Canadian Fibromyalgia Guidelines, available at www.canadianpainsociety.ca/pdf/Fibromyalgia_Guidelines_2012.pdf

\section{APPENDIX 1 \\ Practice recommendations for fibromyalgia (FM): Section 1 Diagnosis}

\section{The clinical evaluation}

1. FM, a condition that can wax and wane over time, should be diagnosed in an individual with diffuse body pain that has been present for at least three months, and who may also have symptoms of fatigue, sleep disturbance, cognitive changes, mood disorder and other somatic symptoms to variable degrees, and when symptoms cannot be explained by some other illness (level 5, grade D) $(2,4,11,46)$.

2. All patients with a symptom suggesting a diagnosis of FM should undergo a physical examination, which should be within normal limits except for tenderness on pressure of soft tissues (ie, hyperalgesia [increased pain following a painful stimulus]) (level 4, grade D) $(2,4,47$ ).

3. Examination of soft tissues for generalized tenderness should be performed by manual palpation with the understanding that the specific tender point examination according to the 1990 American College of Rheumatology diagnostic criteria is not required to confirm a clinical diagnosis of FM (level 5 , grade D) $(1,2)$.

Testing and confirming the diagnosis

4. FM should be diagnosed as a clinical construct, without any confirmatory laboratory test, and with testing limited to simple blood testing including a full blood count and measurement of erythrocyte sedimentation rate and levels of C-reactive protein, creatine kinase and thyroid stimulating hormone. Any additional laboratory or radiographic testing should depend on the clinical evaluation in an individual patient that may suggest some other medical condition (level 5 , grade D) $(48,49)$.

5. The primary care physician should establish a diagnosis of FM as early as possible, without need for confirmation by a specialist, and communicate this diagnosis to the patient. Repeated investigations after diagnosis should be avoided unless driven by the onset of new symptoms or signs on physical examination (level 5, grade D) (13-15,34).

6. The American College of Rheumatology 2010 diagnostic criteria for FM can be used at initial assessment to validate a clinical diagnosis of FM, with the understanding that symptoms vary over time (level 3, grade B) $(1,2,39)$.

Differential diagnosis and coexisting conditions

7. Health care professionals should be aware that some medical or psychological conditions may present with body pain similar to FM, and patients with other medical illnesses may have an associated FM (level 5, grade D) (48,50-53) .

The health care team

8. Management of individuals with FM should be centred in the primary care setting with knowledgeable health care professionals and, ideally, where possible, this care may be augmented by access to a multidisciplinary team (level 1 , grade A) $(33,35)$ or team member to provide support and reassurance (level 3 , grade C) (31,54).

9. Specialist consultation, including referral to a sleep specialist or psychologist, may be required for selected subjects, but continued care by a specialist is not recommended and should be reserved for patients who have failed management in primary care or who have more complex comorbidities (level 5 , grade $\mathrm{D}$ ) (34). 


\section{Education and knowledge}

10. In caring for individuals with FM, health care professionals should be educated regarding the pathogenesis of FM (level 5 , consensus), should be empathetic, open and honest, should not demonstrate negative attitudes and should practice shared decision-making (level 3, grade D) (55-57).

11. Health care professionals should be knowledgeable that objective neurophysiological abnormalities have been identified in patients with FM in the research setting, but are not available in clinical practice for either the diagnosis or care of individuals with FM (level 5 , grade D) $(16,18)$.

12. Patients and health care professionals should acknowledge that genetic factors as well as previous adverse events may have contributed to the development of FM, but focusing excessively on a triggering event could compromise patient care and should, therefore, be discouraged (level 5, grade D) $(22,26,58)$.

Practice recommendations for FM: Section 2

Management

\section{Treatment overview}

13. A treatment strategy for patients with FM should incorporate principles of self-management using a multimodal approach (level 1 (27,28), grade A). It is recommended that attention should be devoted to individual symptoms in a patient-tailored approach, with close monitoring and regular follow-up, particularly in the early stages of management (level 5 , grade D) (27).

14. Patients should be encouraged to identify specific goals regarding health status and quality of life at the initiation of treatment, with re-evaluation of goals during follow-up (level 5, grade D) (54).

Nonpharmacological overview

15. Nonpharmacological strategies with active patient participation should be an integral component of the therapeutic plan for the management of FM (level 1 $(28,59)$, grade A). Encouraging self-efficacy and social support will facilitate the practice of health promoting lifestyles (level $3(60,61)$, grade D).

16. Individuals with FM should be encouraged to pursue as normal a life pattern as possible, using pacing and/or graded incremental activity to maintain or improve function (level 4, grade D) $(62,63)$.

Psychological interventions

17. The attainment of effective coping skills and promotion of self-management can be facilitated by multicomponent therapy (level 5 , grade D) (59).

18. Interventions that improve self-efficacy should be encouraged to help patients cope with symptoms of FM (level 1, grade A) (64).

19. Psychological evaluation and/or counseling may be helpful for persons with FM in view of the associated psychological distress (level 5 , consensus), and patients should be encouraged to acknowledge this distress when present and be informed about the negative impact this may have on well-being (level 3 , grade D) (65).

20. Cognitive behavioural therapy, even for a short time, is useful and can help reduce fear of pain and fear of activity (level 1 (66,67), grade A).

Physical activity

21. Individuals with FM should participate in a graduated exercise program of their choosing to obtain global health benefits and probable effects on FM symptoms (level 1, grade A) (68-74).

Complementary and alternative medicine

22. Patients should be informed that there is currently insufficient evidence to support the recommendation of complimentary and alternative medicine treatments for the management of FM symptoms because they have mostly not been adequately evaluated regarding benefit (level 1, grade A) (75-77).

23. Patients should be encouraged to disclose use of complimentary and alternative medicines to the health care professional, who should be understanding and tolerant of this disclosure and should provide information on current evidence-based understanding of efficacy and risks where available (level 5, consensus).

Pharmacological overview

24. Physicians should identify the most bothersome symptom(s) to help direct pharmacological treatments according to a symptom-based approach. An ideal pharmacological choice may address multiple symptoms simultaneously and may require a combination of medications, in which case attention must be paid to drug interactions (level $5(16,27)$, grade D).

25. Pharmacological treatments should be initiated in low doses with gradual and cautious upward titration to reduce medication intolerance (level 5 , grade $D$ ) (27) with regular evaluation regarding continued efficacy and side effect profile, with the knowledge that drug side effects may appear similar to symptoms of FM (level 5, consensus).

26. Physicians prescribing medications for FM should be open-minded and aware of the broader spectrum of agents available to treat symptoms, and should not confine treatments to a single category of medications (level 5 , consensus).

Traditional pain-relieving therapies

27. Consistent with the WHO step-up analgesic ladder, acetaminophen may be useful in some patients, but with attention to safe dosing (level 5 , consensus).

28. In the event that nonsteroidal anti-inflammatory drugs are prescribed, particularly for associated conditions such as osteoarthritis, they should be used in the lowest dose and for the shortest possible period of time, in view of potential serious adverse events (level 5 , grade D) $(78,79)$.

29. A trial of opioids, beginning with a weak opioid, such as tramadol, should be reserved for treatment of patients with moderate to severe pain that is unresponsive to other treatment modalities (level 2, grade D) $(80,81)$.

30. Strong opioid use is discouraged, and patients who continue to use opioids should show improved pain and function. Health care professionals must monitor for continued efficacy, side effects or evidence of aberrant drug behaviours (level 5, grade D) (82).

Nontraditional pain-relieving therapies

31. A trial of a prescribed pharmacological cannabinoid may be considered in a patient with FM, particularly in the setting of important sleep disturbance (level 3 , grade C) (83-85).

32. The pain-modulating effects of antidepressant medications should be explained to patients with FM to dispel the concept of a primarily psychological complaint (level 5, grade D) (86).

33. All categories of antidepressant medications including tricyclic antidepressants, selective serotonin reuptake inhibitors and serotonin-norepinephrine reuptake inhibitors may be used for treatment of pain and other symptoms in patients with FM (level 1, grade A) $(87,88)$, with choice driven by available evidence for efficacy, physician knowledge, patient characteristics and attention to side effect profile (level 5 , consensus).

34. Anticonvulsant medication use should be explained as having pain-modulating properties and treatment should begin with the lowest possible dose followed by up-titration, with attention to adverse events (level 1, grade A) (89-91).

35. Physicians should be aware that only pregabalin and duloxetine have Health Canada approval for management of FM symptoms and all other pharmacological treatments constitute 'off label use' (level 5, consensus). 
Practice recommendations for FM: Section 3

The outcome

\section{Patient follow-up}

36. Clinical follow-up should be dependent on the judgement of the physician or health care team, with more frequent visits likely during the initial phase of management or until symptoms are stabilized (level 5, consensus).

37. In the continued care of a patient with FM, the development of a new symptom requires clinical evaluation to ensure that symptoms are not due to some other medical illness (level 5, consensus).

38. Patients should be informed that the outcome in many individuals is favourable even if symptoms of FM tend to increase and decrease over time (level 3 , grade B) (92-94).

39. Patients who have experienced previous adverse lifetime events that have impacted on psychological well-being and have not been effectively addressed should be offered appropriate support to facilitate attaining health-related outcome goals (level 5, consensus).

40. Physicians should be alert that factors such as passivity, poor internal locus of control and prominent mood disorder may have a negative influence on outcome (level 5, consensus).

\section{Outcome tools}

41. Outcome can be measured by narrative report of symptom status or patient global impression of change, without need for more complex questionnaires (level 3, grade C) $(36,37)$.

42. Patient goals and their levels of achievement should be recorded as a useful strategy to follow outcome (level 5, consensus).

43. Tender point examination should not be used as an outcome measure (level 3, grade C) (39).

\section{Work recommendations and health cost containment}

44. Physicians should encourage patients to remain in the workforce and, if necessary, may provide recommendations that could help maintain optimal productivity because outcome is generally more favourable for those who are employed (level 3, grade C) (95).

45. Patients with FM on a prolonged sick leave should be encouraged to participate in an appropriate rehabilitation program with focus on improving function, including return to work if possible (level 5, grade D) (42).

46. In persons with FM, other comorbid conditions including depression should be recognized and addressed to reduce health care costs (level 3, grade C) $(96,97)$.

\section{REFERENCES}

1. Wolfe F, Smythe HA, Yunus MB, et al. The American College of Rheumatology 1990. Criteria for the classification of fibromyalgia. Report of the Multicenter Criteria Committee. Arthritis Rheum 1990;33:160-72.

2. Wolfe F, Clauw DJ, Fitzcharles M-A, et al. The American College of Rheumatology preliminary diagnostic criteria for fibromyalgia and measurement of symptom severity. Arthritis Care Res 2010;62:600-10.

3. Fitzcharles M-A, Ste-Marie PA, Goldenberg DL, et al. 2012 Canadian Guidelines for the diagnosis and management of fibromyalgia syndrome. <www.canadianpainsociety.ca/pdf/ Fibromyalgia_Guidelines_2012.pdf $>$ (Accessed September 21, 2012)

4. Mease P, Arnold LM, Choy EH, et al. Fibromyalgia syndrome module at OMERACT 9: Domain construct. J Rheumatol 2009;36:2318-29.

5. McNally JD, Matheson DA, Bakowsky VS. The epidemiology of selfreported fibromyalgia in Canada. Chronic Dis Can 2006;27:9-16.

6. Lachaine J, Beauchemin C, Landry P-A. Clinical and economic characteristics of patients with fibromyalgia syndrome. Clin J Pain 2010;26:284-90.

7. Carville SF, Arendt-Nielsen S, Bliddal H, et al. EULAR evidencebased recommendations for the management of fibromyalgia syndrome. Ann Rheum Dis 2008;67:536-41.

8. Hauser W, Eich W, Herrmann M, Nutzinger DO, Schiltenwolf M, Henningsen P. Fibromyalgia syndrome: Classification, diagnosis, and treatment. Dtsch 2009;106:383-91.

9. Burckhardt C, Goldenberg D, Crofford L, et al. Guideline for the management of fibromyalgia syndrome. Pain in adults and children. APS Clinical practice guideline Series No. 4 Glenview, Illinois: American Pain Society; 2005.

10. Howick J, Chalmers I, Glasziou P, et al. The Oxford 2011 Table of Evidence. Oxford Centre for Evidence-Based Medicine. $<$ www.cebm.net/index.aspx?o=5653?> (Accessed 2012)

11. Walitt B, Fitzcharles MA, Hassett AL, Katz RS, Hauser W, Wolfe F. The longitudinal outcome of fibromyalgia: A study of 1555 patients. J Rheumatol 2011;38:2238-46.

12. Shir Y, Fitzcharles MA. Should rheumatologists retain ownership of fibromyalgia? J Rheumatol 2009;36:667-70.

13. Hughes G, Martinez C, Myon E, Taieb C, Wessely S. The impact of a diagnosis of fibromyalgia on health care resource use by primary care patients in the UK: An observational study based on clinical practice. Arthritis Rheum 2006;54:177-83.

14. Annemans L, Wessely S, Spaepen E, et al. Health economic consequences related to the diagnosis of fibromyalgia syndrome. Arthritis Rheum 2008;58:895-902.
15. Annemans L, Le Lay K, Taieb C. Societal and patient burden of fibromyalgia syndrome. Pharmacoeconomics 2009;27:547-59.

16. Perrot S, Dickenson AH, Bennett RM. Fibromyalgia: Harmonizing science with clinical practice considerations. Pain Pract 2008;8:177-89.

17. Abeles AM, Pillinger MH, Solitar BM, Abeles M. Narrative review: The pathophysiology of fibromyalgia. Ann Intern Med 2007;146:726-34.

18. Price DD, Staud R. Neurobiology of fibromyalgia syndrome. J Rheumatol Suppl 2005;75:22-8.

19. Buskila D, Neumann L. Fibromyalgia syndrome (FM) and nonarticular tenderness in relatives of patients with FM. J Rheumatol 1997;24:941-4.

20. Buskila D, Neumann L, Hazanov I, Carmi R. Familial aggregation in the fibromyalgia syndrome. Semin Arthritis Rheum 1996;26:605-11.

21. Smith SB, Maixner DW, Fillingim RB, et al. Large candidate gene association study reveals genetic risk factors and therapeutic targets for fibromyalgia. Arthritis Rheum 2012;64:584-93.

22. Buskila D, Sarzi-Puttini P. Biology and therapy of fibromyalgia. Genetic aspects of fibromyalgia syndrome. Arthritis Res Ther 2006;8:218.

23. McBeth J, Silman AJ, Gupta A, et al. Moderation of psychosocial risk factors through dysfunction of the hypothalamic-pituitaryadrenal stress axis in the onset of chronic widespread musculoskeletal pain: Findings of a population-based prospective cohort study. Arthritis Rheum 2007;56:360-71.

24. Gupta A, Silman AJ, Ray D, et al. The role of psychosocial factors in predicting the onset of chronic widespread pain: Results from a prospective population-based study. Rheumatology (Oxford) 2007;46:666-71.

25. Boisset-Pioro MH, Esdaile JM, Fitzcharles MA. Sexual and physical abuse in women with fibromyalgia syndrome. Arthritis Rheum 1995;38:235-41.

26. Greenfield S, Fitzcharles MA, Esdaile JM. Reactive fibromyalgia syndrome. Arthritis Rheum 1992;35:678-81.

27. Boomershine CS, Crofford LJ. A symptom-based approach to pharmacologic management of fibromyalgia. Nat Rev Rheumatol 2009;5:191-9.

28. Rossy LA, Buckelew SP, Dorr N, et al. A meta-analysis of fibromyalgia treatment interventions. Ann Behav Med 1999;21:180-91.

29. Dobkin PL, Liu A, Abrahamowicz M, et al. Predictors of disability and pain six months after the end of treatment for fibromyalgia. Clin J Pain 2010;26:23-9.

30. Kroese ME, Schulpen GJ, Sonneveld HM, Vrijhoef HJ. Therapeutic approaches to fibromyalgia in the Netherlands: A comparison between 1998 and 2005. J Eval Clin Pract 2008;14:321-5. 
31. Kroese ME, Schulpen GJ, Bessems MC, et al. Substitution of specialized rheumatology nurses for rheumatologists in the diagnostic process of fibromyalgia: A randomized controlled trial. Arthritis Rheum 2008;59:1299-305.

32. Buskila D, Neumann L, Sibirski D, Shvartzman P. Awareness of diagnostic and clinical features of fibromyalgia among family physicians. Fam Pract 1997;14:238-41.

33. Shleyfer E, Jotkowitz A, Karmon A, Nevzorov R, Cohen H, Buskila D. Accuracy of the diagnosis of fibromyalgia by family physicians: Is the pendulum shifting? J Rheumatol 2009;36:170-3.

34. Boyer AL, Mira MAP, Calatayud NP, Lopez-Roig S, Cantero MCT. Comparing fibromyalgia patients from primary care and rheumatology settings: Clinical and psychosocial features. Rheumatol Int 2009;29:1151-60

35. Garcia-Campayo J, Magdalena J, Magallon R, Fernandez-Garcia E, Salas M, Andres E. A meta-analysis of the efficacy of fibromyalgia treatment according to level of care. Arthritis Res Ther 2008;10:R81.

36. Geisser ME, Clauw DJ, Strand V, Gendreau RM, Palmer R, Williams DA. Contributions of change in clinical status parameters to Patient Global Impression of Change (PGIC) scores among persons with fibromyalgia treated with milnacipran. Pain 2010;149:373-8.

37. Bakker C, Rutten M, van Santen-Hoeufft M, et al. Patient utilities in fibromyalgia and the association with other outcome measures. J Rheumatol 1995;22:1536-43.

38. Asbring P, Narvanen A-L. Ideal versus reality: Physicians perspectives on patients with chronic fatigue syndrome (CFS) and fibromyalgia. Soc Sci Med 2003;57:711-20.

39. Bidari A, Ghavidel-Parsa B, Ghalehbaghi B. Reliability of ACR criteria over time to differentiate classic fibromyalgia from nonspecific widespread pain syndrome: A 6-month prospective cohort study. Mod Rheumatol 2009;19:663-9.

40. Wolfe F, Anderson J, Harkness D, et al. Work and disability status of persons with fibromyalgia. J Rheumatol 1997;24:1171-8.

41. Henriksson CM, Liedberg GM, Gerdle B. Women with fibromyalgia: Work and rehabilitation. Disabil Rehabil 2005;27:685-94.

42. Skouen JS, Grasdal A, Haldorsen EMH. Return to work after comparing outpatient multidisciplinary treatment programs versus treatment in general practice for patients with chronic widespread pain. Eur J Pain 2006;10:145-52.

43. Penrod JR, Bernatsky S, Adam V, Baron M, Dayan N, Dobkin PL. Health services costs and their determinants in women with fibromyalgia. J Rheumatol 2004;31:1391-8.

44. Rivera J, Rejas J, Esteve-Vives J, Vallejo MA, Groupo I. Resource utilisation and health care costs in patients diagnosed with fibromyalgia in Spain. Clin Exp Rheumatol 2009;27(5 Suppl 56):S39-45.

45. Wolfe F, Anderson J, Harkness D, et al. A prospective, longitudinal, multicenter study of service utilization and costs in fibromyalgia. Arthritis Rheum 1997;40:1560-70.

46. Wolfe F, Anderson J, Harkness D, et al. Health status and disease severity in fibromyalgia: Results of a six-center longitudinal study. Arthritis Rheum 1997;40:1571-9.

47. Katz RS, Wolfe F, Michaud K. Fibromyalgia diagnosis: A comparison of clinical, survey, and American College of Rheumatology criteria. Arthritis Rheum 2006;54:169-76.

48. Goldenberg DL. Diagnosis and differential diagnosis of fibromyalgia. Am J Med 2009;122(12 Suppl):S14-21.

49. Yunus MB. Fibromyalgia syndrome: Clinical features and spectrum. J Musculoskel Pain 1994;2:5-21.

50. Fitzcharles MA, Boulos P. Inaccuracy in the diagnosis of fibromyalgia syndrome: Analysis of referrals. Rheumatology (Oxford) 2003;42:263-7.

51. Fitzcharles MA, Esdaile JM. The overdiagnosis of fibromyalgia syndrome. Am J Med 1997;103:44-50.

52. Hsu VM, Patella SJ, Sigal LH. "Chronic Lyme disease" as the incorrect diagnosis in patients with fibromyalgia. Arthritis Rheum 1993;36:1493-500.

53. Kozanoglu E, Canataroglu A, Abayli B, Colakoglu S, Goncu K. Fibromyalgia syndrome in patients with hepatitis $\mathrm{C}$ infection. Rheumatol Int 2003;23:248-51.

54. Becker H, Stuifbergen A, Taxis C, Beal CC, Pierini DM. The use of goal attainment scaling to facilitate and assess individualized change in a wellness intervention for women with fibromyalgia syndrome. J Holist Nurs 2009;27:232-40.

55. Haugli L, Strand E, Finset A. How do patients with rheumatic disease experience their relationship with their doctors? A qualitative study of experiences of stress and support in the doctor-patient relationship. Patient Educ Couns 2004;52:169-74.
56. Bieber C, Muller KG, Blumenstiel K, et al. A shared decisionmaking communication training program for physicians treating fibromyalgia patients: Effects of a randomized controlled trial. J Psychosom Res 2008;64:13-20.

57. Walker EA, Katon WJ, Keegan D, Gardner G, Sullivan M. Predictors of physician frustration in the care of patients with rheumatological complaints. Gen Hosp Psychiatry 1997;19:315-23.

58. Jones GT, Power C, Macfarlane GJ. Adverse events in childhood and chronic widespread pain in adult life: Results from the 1958 British Birth Cohort Study. Pain 2009;143:92-6.

59. Hauser W, Bernardy K, Arnold B, Offenbacher M, Schiltenwolf M. Efficacy of multicomponent treatment in fibromyalgia syndrome: A meta-analysis of randomized controlled clinical trials. Arthritis Rheum 2009;61:216-24.

60. Beal CC, Stuifbergen AK, Brown A. Predictors of a health promoting lifestyle in women with fibromyalgia syndrome. Psychol Health Med 2009;14:343-53.

61. Du Plessis M, Steel HR, Moller AT. The relationship between psychosocial variables and measures of health status in fibromyalgia. S Afr Fam Pract 2009;51:42-5.

62. Henriksson C, Burckhardt C. Impact of fibromyalgia on everyday life: A study of women in the USA and Sweden. Disabil Rehabil 1996;18:241-8.

63. Henriksson C, Liedberg G. Factors of importance for work disability in women with fibromyalgia. J Rheumatol 2000;27:1271-6.

64. Hadhazy VA, Ezzo J, Creamer P, Berman BM. Mind-body therapies for the treatment of fibromyalgia. A systematic review. J Rheumatol 2000;27:2911-8.

65. Hughes L. Physical and psychological variables that influence pain in patients with fibromyalgia. Orthop Nurs 2006;25:112-9.

66. Bennett R, Nelson D. Cognitive behavioral therapy for fibromyalgia. Nat Clin Pract Rheumatol 2006;2:416-24.

67. Bernardy K, Fuber N, Kollner V, Hauser W. Efficacy of cognitivebehavioral therapies in fibromyalgia syndrome: A systematic review and metaanalysis of randomized controlled trials. J Rheumatol 2010;37:1991-2005

68. Brosseau L, Wells GA, Tugwell P, et al. Ottawa Panel evidencebased clinical practice guidelines for strengthening exercises in the management of fibromyalgia: Part 2. Phys Ther 2008;88:873-86.

69. Brosseau L, Wells GA, Tugwell P, et al. Ottawa Panel evidencebased clinical practice guidelines for aerobic fitness exercises in the management of fibromyalgia: Part 1. Phys Ther 2008;88:857-71.

70. Busch A, Schachter CL, Peloso PM, Bombardier C. Exercise for treating fibromyalgia syndrome. Cochrane Database Syst Rev 2002(3):CD003786.

71. Busch AJ, Barber KA, Overend TJ, Peloso PM, Schachter CL. Exercise for treating fibromyalgia syndrome. Cochrane Database Syst Rev 2007(4):CD003786.

72. Busch AJ, Schachter CL, Overend TJ, Peloso PM, Barber KAR. Exercise for fibromyalgia: A systematic review. J Rheumatol 2008;35:1130-44.

73. Langhorst J, Musial F, Klose P, Hauser W. Efficacy of hydrotherapy in fibromyalgia syndrome - a meta-analysis of randomized controlled clinical trials. Rheumatology (Oxford) 2009;48:1155-9.

74. Perraton L, Machotka Z, Kumar S. Components of effective randomized controlled trials of hydrotherapy programs for fibromyalgia syndrome: A systematic review. J Pain Res 2009;2:165-73.

75. Cao H, Liu J, Lewith GT. Traditional Chinese medicine for treatment of fibromyalgia: A systematic review of randomized controlled trials. J Altern Complement Med 2010;16:397-409.

76. De Silva V, El-Metwally A, Ernst E, Lewith G, Macfarlane GJ. Evidence for the efficacy of complementary and alternative medicines in the management of fibromyalgia: A systematic review. Rheumatology (Oxford) 2010;49:1063-8.

77. Langhorst J, Klose P, Musial F, Irnich D, Hauser W. Efficacy of acupuncture in fibromyalgia syndrome: A systematic review with a metaanalysis of controlled clinical trials. Rheumatology 2010;49:778-88.

78. Tannenbaum H, Bombardier C, Davis P, Russell AS. An evidencebased approach to prescribing nonsteroidal antiinflammatory drugs. Third Canadian Consensus Conference. J Rheumatol 2006;33:140-57.

79. Rao SG, Clauw DJ. The management of fibromyalgia. Drugs Today 2004:40:539-54.

80. Bennett RM, Kamin M, Karim R, Rosenthal N. Tramadol and acetaminophen combination tablets in the treatment of fibromyalgia pain: A double-blind, randomized, placebo-controlled study. Am J Med 2003;114:537-45. 
81. Biasi G, Manca S, Manganelli S, Marcolongo R. Tramadol in the fibromyalgia syndrome: A controlled clinical trial versus placebo. Int J Clin Pharmacol Res 1998;18:13-9.

82. Furlan AD, Reardon R, Weppler C. Opioids for chronic noncancer pain: A new Canadian practice guideline. CMAJ 2010;182:923-30.

83. Skrabek RQ, Galimova L, Ethans K, Perry D. Nabilone for the treatment of pain in fibromyalgia. J Pain 2008;9:164-73.

84. Ware MA, Fitzcharles MA, Joseph L, Shir Y. The effects of nabilone on sleep in fibromyalgia: Results of a randomized controlled trial. Anesth Analg 2010;110:604-10.

85. Lynch ME, Campbell F. Cannabinoids for treatment of chronic non-cancer pain; a systematic review of randomized trials. Br J Clin Pharmacol 2011;72:735-44.

86. Goldenberg DL, Clauw DJ, Fitzcharles MA. New concepts in pain research and pain management of the rheumatic diseases. Semin Arthritis Rheum 2011;41:319-34.

87. Uceyler N, Hauser W, Sommer C. A systematic review on the effectiveness of treatment with antidepressants in fibromyalgia syndrome. Arthritis Rheum 2008;59:1279-98.

88. Hauser W, Bernardy K, Uceyler N, Sommer C. Treatment of fibromyalgia syndrome with antidepressants: A meta-analysis. JAMA 2009;301:198-209.

89. Holtedahl R. [Questionable documentation of the effect of pregabalin in fibromyalgia]. Tidsskr Nor Laegeforen 2010;130:1032-6.
90. Hauser W, Bernardy K, Uceyler N, Sommer C. Treatment of fibromyalgia syndrome with gabapentin and pregabalin - a metaanalysis of randomized controlled trials. Pain 2009;145:69-81.

91. Moore RA, Straube S, Wiffen PJ, Derry S, McQuay HJ. Pregabalin for acute and chronic pain in adults. Cochrane Database Syst Rev 2009(3):CD007076.

92. Granges G, Zilko P, Littlejohn GO. Fibromyalgia syndrome: Assessment of the severity of the condition 2 years after diagnosis. J Rheum 1994;21:523-9.

93. Fitzcharles M-A, Costa DD, Poyhia R. A study of standard care in fibromyalgia syndrome: A favorable outcome. J Rheumatol 2003;30:154-9.

94. Martinez JE, Ferraz MB, Sato EI, Atra E. Fibromyalgia versus rheumatoid arthritis: A longitudinal comparison of the quality of life. J Rheumatol 1995;22:270-4.

95. Reisine S, Fifield J, Walsh S, Forrest DD. Employment and health status changes among women with fibromyalgia: A five-year study. Arthritis Rheum 2008;59:1735-41.

96. Walen HR, Cronan PA, Bigatti SM. Factors associated with healthcare costs in women with fibromyalgia. Am J Manag Care 2001;7 Spec No:SP39-47.

97. Robinson RL, Birnbaum HG, Morley MA, Sisitsky T, Greenberg PE, Wolfe F. Depression and fibromyalgia: Treatment and cost when diagnosed separately or concurrently. J Rheumatol 2004;31:1621-9. 


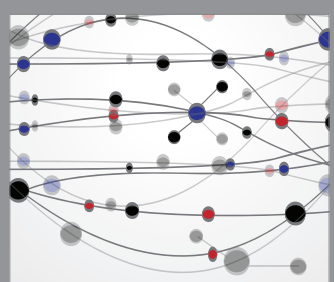

The Scientific World Journal
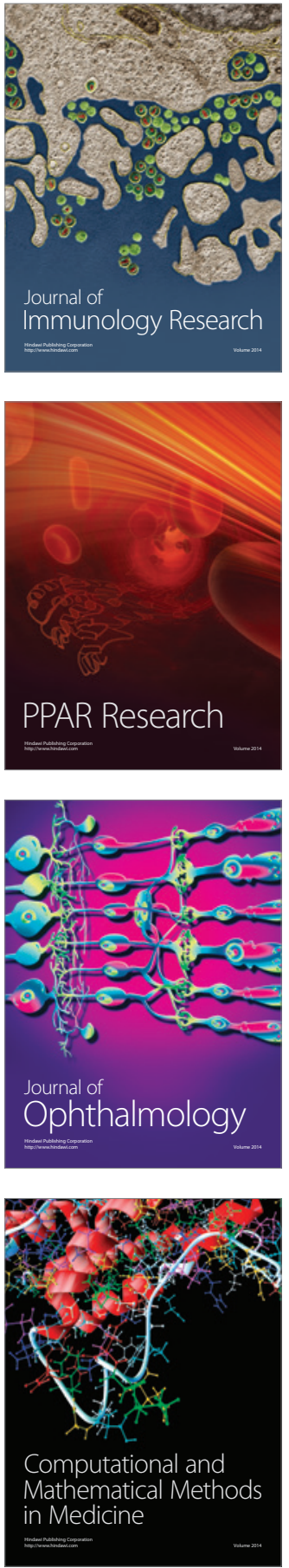

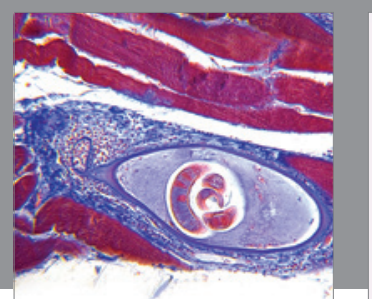

Gastroenterology Research and Practice

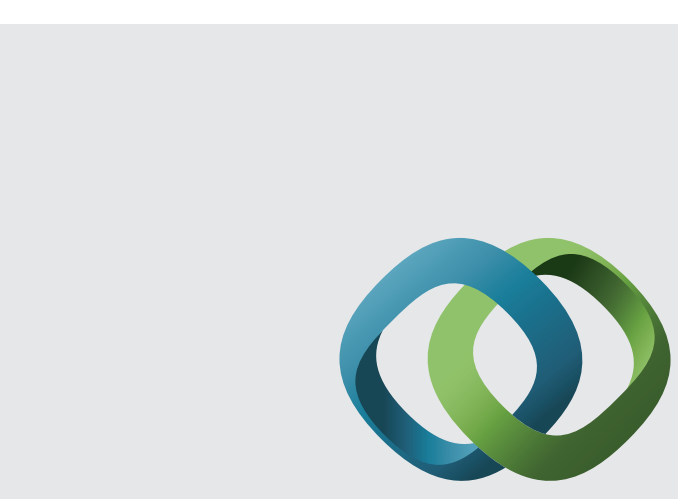

\section{Hindawi}

Submit your manuscripts at

http://www.hindawi.com
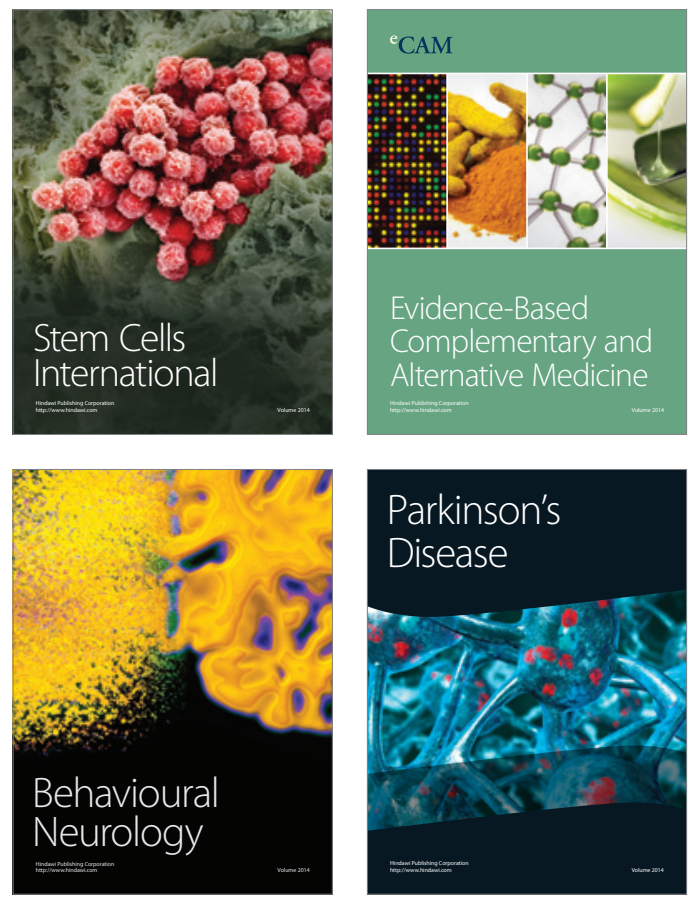
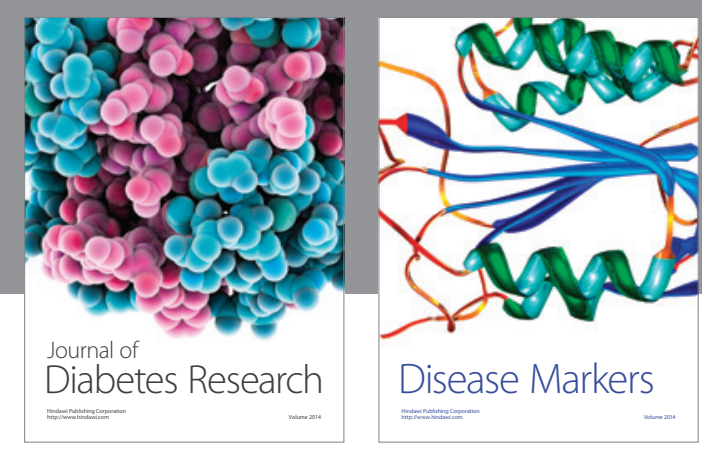

Disease Markers
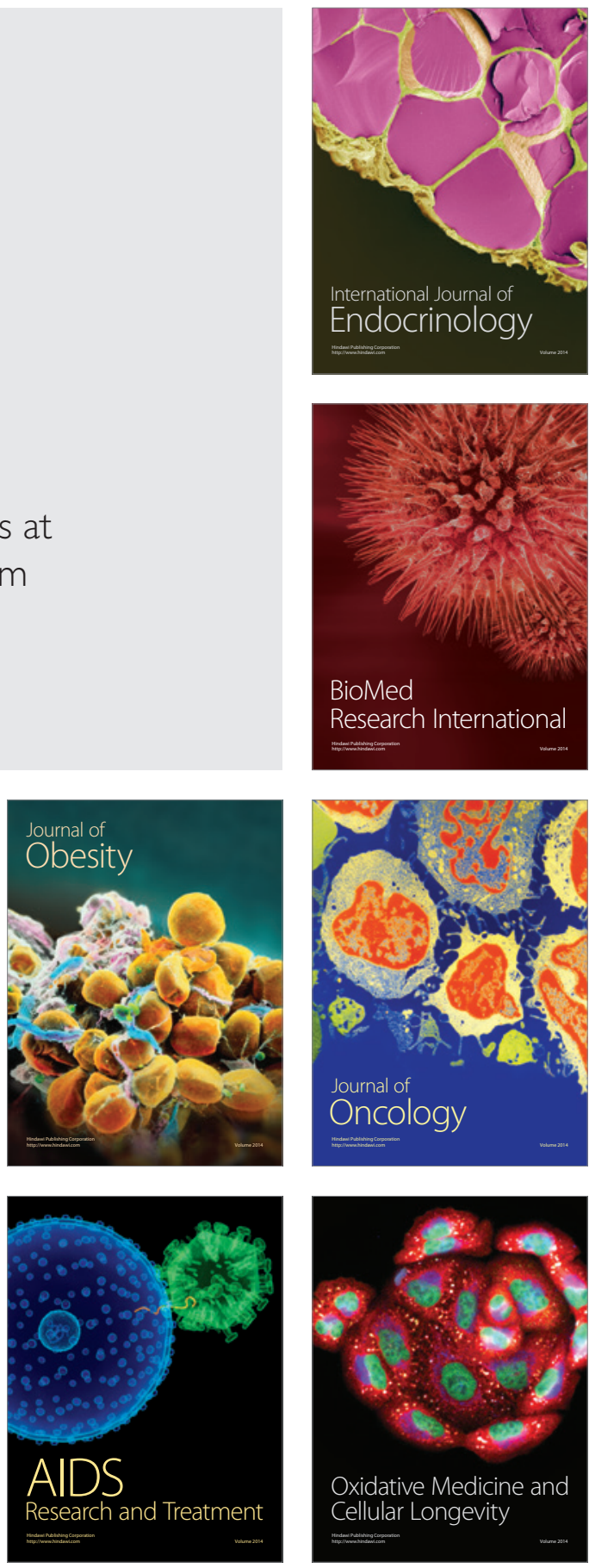